\title{
NECESSIDADES DE AUTOCUIDADO NO PERÍODO PÓS-PARTO IDENTIFICADAS EM GRUPOS DE PUÉRPERAS E ACOMPANHANTES
}

\section{SELF CARE NEEDS POSTPARTUM FROM GROUPS OF POSTPARTUM WOMEN AND CAREGIVERS}

\section{LAS NECESIDADES DE AUTOCUIDADO EN EL PERÍODO POSTPARTO IDENTIFICADOS EN GRUPOS DE MUJERES Y ACOMPANHANTES}

\author{
Eryjosy Marculino Guerreiro Barbosa ${ }^{1}$, Dafne Paiva Rodrigues ${ }^{2}$, Albertina Antonielly Sydney de Sousa $^{3}$, Ana \\ Virginia de Melo Fialho ${ }^{4}$, Perla Guimarães Feitosa ${ }^{5}$, Anna Laurita Pequeno Landim ${ }^{6}$
}

\section{RESUMO}

Objetivo: Identificar as necessidades de autocuidado no pós-parto em grupos de puérperas e acompanhantes. Métodos: Estudo descritivo e exploratório, por meio de grupo focal. Participaram 36 mulheres, sendo 30 puérperas e seis acompanhantes. Utilizou-se uma pergunta indutora (Quais as principais necessidades de autocuidado da mulher no período pós-parto?), da qual emergiram as necessidades de autocuidado no período pós-parto, que foram agrupadas por similaridade de conteúdo: higiene, cuidado com os pontos, cuidados do cabelo e pele, nutrição, cuidado com as mamas, benefícios da amamentação para a mulher, retorno da atividade sexual, planejamento familiar, indicação e retorno da atividade física, perda de peso, uso de cinta, repouso, atividades do lar, comparecimento às consultas puerperais, saúde mental e apoio familiar. Conclusões: Possibilitou-se conhecer as reais demandas das puérperas a partir da identificação de suas necessidades de autocuidado e expectativas.

Descritores: Autocuidado; Teoria de Enfermagem; Período pós-parto; Mulheres; Enfermagem.

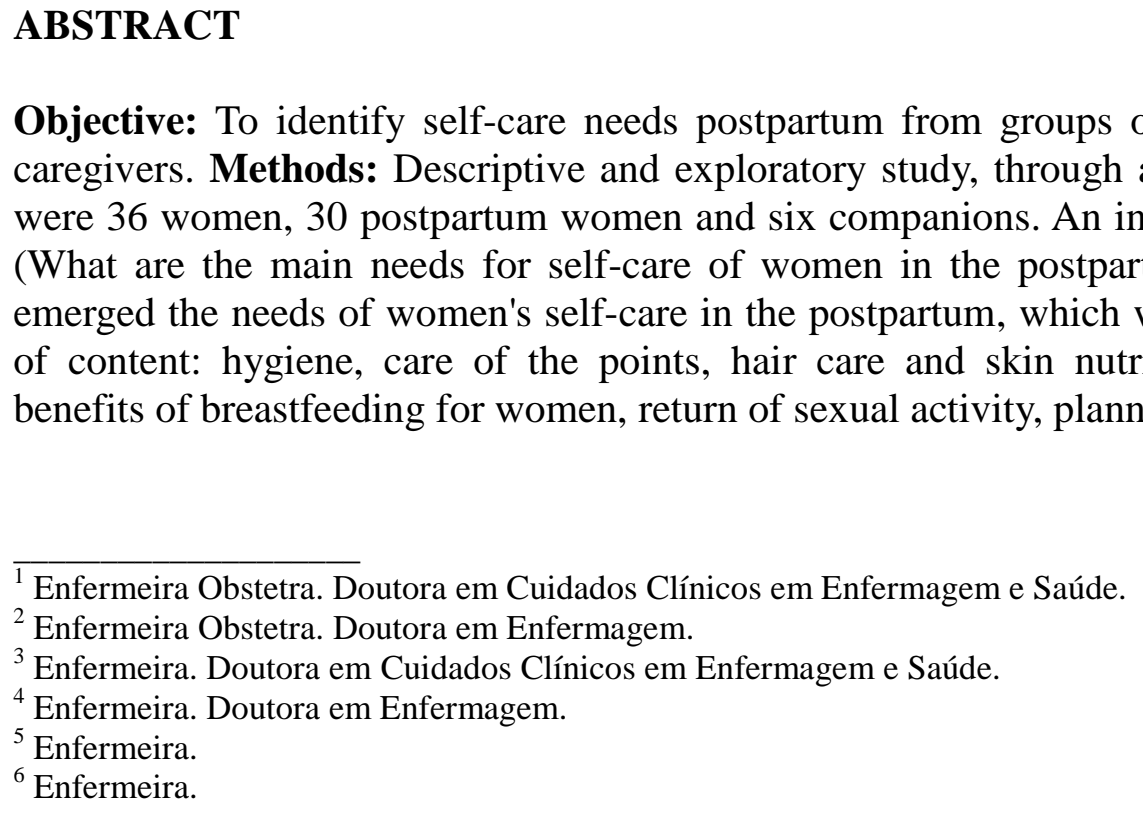

\footnotetext{
${ }^{1}$ Enfermeira Obstetra. Doutora em Cuidados Clínicos em Enfermagem e Saúde.

${ }^{2}$ Enfermeira Obstetra. Doutora em Enfermagem.

${ }^{3}$ Enfermeira. Doutora em Cuidados Clínicos em Enfermagem e Saúde.

${ }^{4}$ Enfermeira. Doutora em Enfermagem.

${ }^{5}$ Enfermeira.

${ }^{6}$ Enfermeira.
}

Objective: To identify self-care needs postpartum from groups of postpartum women and caregivers. Methods: Descriptive and exploratory study, through a focal group. Participants were 36 women, 30 postpartum women and six companions. An inductive question was used (What are the main needs for self-care of women in the postpartum period?), from which emerged the needs of women's self-care in the postpartum, which were grouped by similarity of content: hygiene, care of the points, hair care and skin nutrition, care of the breasts, benefits of breastfeeding for women, return of sexual activity, planning family, indication and 
return of physical activity, weight loss, belt use, home, home activities, attending at puerperal medical appointments, mental health and family support. Conclusions: It was possible to know the real demands of postpartum women from the identification of their self-care needs and expectations.

Descriptors: Self care; Nursing Theory; Postpartum period; Women; Nursing.

\section{RESUMEN}

Objetivo: Identificar las necesidades de autocuidado en el postparto desde grupos de mujeres y cuidadores. Métodos: Estudio descriptivo y exploratorio, por medio de un grupo focal. Participaron 36 mujeres, siendo 30 puérperas y seis compañeros. Se utilizó una pregunta inductora (¿Cuáles son las principales necesidades de autocuidado de la mujer en el período post-parto?), de la cual emergieron las necesidades de autocuidado en el período postparto, que fueron agrupadas por similaridad de contenido: higiene, cuidado con los puntos, el cabello y el cuidado de la piel, la nutrición, el cuidado de los pechos, los beneficios de la lactancia materna para las mujeres, el retorno de la actividad sexual, la planificación familiar, la indicación y el retorno de la actividad física, la pérdida de peso, el uso de correa, descanso, actividades en el hogar, asistiendo a citas médicas puerperales, salud mental y apoyo familiar. Conclusiones: Permitió conocer las demandas reales de puérperas desde la identificación de sus necesidades de autocuidado y las expectativas.

Descriptores: Autocuidado; Teoría de Enfermería; Período de Postparto; Mujeres; Enfermería.

\section{INTRODUÇÃO}

O período pós-parto é marcado como uma fase de grandes modificações biopsicossociais na vida da mulher que experimenta a maternidade. Caracteriza-se pela maior necessidade de cuidado e proteção, tendo em vista que muitas das mudanças envolvem questões de saúde tanto da mãe quanto do bebê. ${ }^{1-2}$ Aspectos relacionados ao autocuidado, cuidados com o recém-nascido, acesso aos serviços de saúde e a satisfação da mulher com a assistência recebida, são importantes premissas a serem atendidas para prover o transcorrer satisfatório desta fase. ${ }^{2}$

Nesse contexto, salienta-se a importância do cuidado de Enfermagem estabelecido em uma relação de confiança e empatia, na qual a puérpera se sinta contemplada em suas necessidades. Tal cuidado permitirá ao enfermeiro, por meio de seu julgamento clínico, definir metas e propor intervenções significativas para esse contexto de novas experiências e significados na vida da mulher. $^{3}$

Para embasar cientificamente o cuidado, o enfermeiro dispõe de um amplo leque de teorias, as quais orientam a prática e o auxiliam na identificação das necessidades da clientela, melhorando sua saúde e bem-estar. ${ }^{4}$ Além disso, devem contribuir para que os sujeitos assumam seu papel de copartícipes nesse processo, reforçando-se o autocuidado.

O autocuidado é uma técnica utilizada para empoderar o sujeito para se 
cuidar. Assim, como sujeito ativo do processo, pode modificar suas atitudes e assumir novos comportamentos. Neste sentido, atua como agente de transformação para manter a saúde e prevenir complicações. ${ }^{5}$ Busca o cuidar de si mesmo, do corpo e da mente, melhorar o estilo de vida, conhecer e controlar os fatores de risco que levam às doenças e adotar medidas para prevení-las. $^{6}$

Nesse contexto, pode-se destacar a Teoria do Autocuidado de Dorothea Orem, classificada como de amplo alcance e pertencente à categoria de necessidades/problemas, buscando preenchê-los ou corrigi-los. ${ }^{7} \mathrm{Um}$ de seus pressupostos é que todos os seres humanos têm potencial para desenvolver suas habilidades intelectuais e práticas, além da motivação essencial para o autocuidado, e se apresenta baseada em importantes conceitos, a saber: ${ }^{7}$

1) Autocuidado: é o desempenho ou a prática de atividades que os indivíduos realizam em seu benefício para manter a vida, a saúde e o bem-estar. Quando o autocuidado é efetivamente realizado, ajuda a manter a integridade estrutural e o funcionamento humano, contribuindo para o seu desenvolvimento; ${ }^{7}$

2) Ação de autocuidado e fatores condicionantes básicos: é a capacidade humana ou o poder de engajar-se no autocuidado. Para tanto, o indivíduo é afetado por fatores condicionantes básicos como: idade, sexo, desenvolvimento, estado de saúde, orientação sociocultural, sistema de atendimento de saúde (isto é, modalidades de diagnósticos e de tratamentos), sistema familiar, padrões de vida (por exemplo, engajamento regular em atividades), ambientais e adequação e disponibilidade de recursos; ${ }^{7}$

3) Demanda terapêutica de autocuidado: é a totalidade de ações de autocuidado a serem desempenhadas para preencher exigências conhecidas de autocuidado, a partir de métodos válidos e conjuntos de operações e ações relacionadas. ${ }^{7}$

Outro conceito importante da Teoria diz respeito aos 'requisitos de autocuidado', que são divididos em universais (comuns a todos os seres humanos), do desenvolvimento (necessários para $\mathrm{o}$ crescimento $\mathrm{e} \quad \mathrm{o}$ desenvolvimento) e de desvio da saúde (associados aos déficits de saúde). São requisitos de autocuidado universais: manutenção de uma ingesta suficiente de ar, água e alimentos; provisão de cuidados associados com os processos de eliminação e os excrementos; manutenção do equilíbrio entre a atividade e o repouso e entre a solidão e a interação social; prevenção dos perigos à vida humana, ao funcionamento e ao bem-estar do ser 
humano; promoção do funcionamento e do desenvolvimento do ser humano dentro dos grupos sociais, de acordo com o potencial, as limitações conhecidas e o desejo de ser normal. ${ }^{7}$

Os requisitos de desenvolvimento de autocuidado são tanto as expressões especializadas de autocuidado universais, que foram particularizadas por processos de desenvolvimento, quanto as novas, as quais são derivadas de uma condição ou associadas a algum evento (por exemplo, adaptação às modificações do corpo). $\mathrm{O}$ autocuidado no desvio de saúde é exigido em condições de doença ou de lesão ou pode resultar das medidas médicas exigidas para diagnosticar ou corrigir determinada condição. ${ }^{7}$

No contexto do pós-parto, considerando-se as necessidades maternas evidenciadas principalmente pelos requisitos de desenvolvimento do autocuidado, uma das principais ações a serem aplicadas pela enfermagem pode ser centrada nas ações educativas. Mediante o ensino do autocuidado, o enfermeiro tem a possibilidade de propiciar condições mais saudáveis e de maior autonomia às mulheres. ${ }^{9}$

A educação em saúde assume papel primordial no âmbito do autocuidado de puérperas por incentivar hábitos e comportamentos de saúde por meio de um apoio informacional horizontalizado e compartilhado. ${ }^{10}$ Atualmente, diversas tecnologias educacionais têm se destacado como ferramentas facilitadoras de comportamentos saudáveis e mais orientados no âmbito do relacionamento terapêutico. Além disso, o enfermeiro leva em consideração a história de vida de cada mulher, respeitando o saber comum, aliando-o à sua práxis cientificamente embasada. $^{11}$

Logo, é importante que o enfermeiro esclareça dúvidas e oriente a mulher nas ações de autocuidado que podem e devem ser exercidas durante $\mathrm{o}$ puerpério e, para isso, é fundamental que esse profissional tenha aproximação teórica para desenvolver assistência direcionada às reais necessidades das puérperas.

Com base no exposto, este estudo objetivou identificar as necessidades de autocuidado no pós-parto em grupos de puérperas e acompanhantes para a elaboração de uma tecnologia educativa voltada ao autocuidado desta clientela.

\section{MÉTODOS}

Trata-se de um recorte da tese "Construção e validação de uma tecnologia educativa sobre o autocuidado de mulheres no pós-parto", que contempla a Fase 1 (Sistematização de conteúdo) do processo 
de construção da cartilha proposto por Reberte, Hoga e Gomes. ${ }^{12}$ Para a construção do material, sistematizou-se seu conteúdo através da elaboração de uma revisão integrativa pelos autores ${ }^{13}$, a qual foi norteada pela seguinte questão: com a seguinte questão norteadora: Que tecnologias educativas vêm sendo desenvolvidas ou utilizadas por enfermeiros para o (auto)cuidado de mulheres no período pós-parto? A complementação dos dados foi realizada por meio de grupos de puérperas e acompanhantes.

A revisão seguiu as etapas propostas por Mendes, Silveira e Galvão ${ }^{14}$, a saber: 1) identificação do tema e seleção da hipótese ou questão de pesquisa; 2) estabelecimento de critérios para inclusão e exclusão de estudos/amostragem ou busca na literatura; 3) definição das informações a serem extraídas dos estudos selecionados/categorização dos estudos; 4) avaliação dos estudos incluídos na revisão integrativa; 5) interpretação dos resultados; e 6) apresentação da revisão/síntese do conhecimento.

Os dados foram coletados em julho de 2014 nas seguintes bases e portais: Cumulative Index to Nursing \& Allied Health Literature (CINAHL), SCOPUS, PubMed, Scientific Electronic Library Online (SciELO), Literatura Latino- americana e do Caribe em Ciencias da Saude (LILACS) e Cochrane. Utilizaramse os descritores disponíveis no Medical Subject Headings (MeSH) e operadores booleanos: postpartum period AND educational technology AND nursing AND self care. Algumas bases de dados apresentam descritores próprios, os quais foram acrescentados à busca: technology e education (CINAHL); technology (LILACS); technology assessments (Cochrane).

Foram incluídos os artigos publicados de janeiro de 2004 a julho de 2014; disponíveis na íntegra em português, inglês, espanhol ou francês; foram excluídas duplicidades, revisões integrativas e sistemáticas, teses e dissertações. Após a aplicação dos critérios, a amostra foi composta por 24 artigos.

Com base na revisão realizada pelas autoras, foi possível selecionar o conteúdo inicial a ser abordado na cartilha educativa sobre o autocuidado de mulheres no pós-parto. Despontaram como principais temas: higiene, nutrição da mãe, suplementação de ferro pela mãe, cuidados com as mamas, retorno da atividade sexual, planejamento familiar, indicação e retorno de atividade física, perda de peso, repouso, relaxamento, saúde mental, direitos da mulher, vacinas da mulher no 
pós-parto, comparecimento às consultas puerperais e adaptação materna no período. $^{13}$

Para complementar os dados oriundos da revisão, o conteúdo para embasar a construção da cartilha também foi identificado por meio de estudo descritivo e exploratório, por meio de grupo focal com puérperas e acompanhantes.

Esses dados foram coletados nos meses de fevereiro e março de 2015, em reuniões conduzidas pela pesquisadora em unidades de alojamento conjunto de um hospital universitário de Fortaleza-CE. Participaram 36 mulheres, sendo 30 puérperas e seis acompanhantes (mulheres que já vivenciaram a experiência da maternidade), divididas em nove grupos de três a cinco mulheres cada.

Para a condução do grupo focal, utilizou-se a pergunta indutora: Quais as principais necessidades de autocuidado da mulher no período pós-parto? A partir dela, as participantes verbalizaram suas demandas e os pesquisadores as agruparam por similaridade de conteúdo. Esta técnica grupal permitiu constatar suas reais necessidades e possíveis mudanças (supressões e acréscimos) na seleção do conteúdo da cartilha.

Inicialmente, as participantes foram convidadas a expressar suas dúvidas e necessidades educativas sobre $\mathrm{o}$ autocuidado no período pós-parto. Em seguida, as dúvidas foram dirimidas, na medida do possível, e perguntou-se às participantes se havia mais algum tema que elas gostariam que fosse abordado. Ao final da reunião, as participantes avaliaram quais os principais conteúdos contemplados.

As reuniões foram gravadas $\mathrm{e}$ transcritas literalmente. Em seguida, as necessidades/falas que emergiram foram analisadas e agrupadas por similaridade de conteúdo, procedendo-se à discussão das mesmas com base na literatura pertinente ao tema e utilizando-os para direcionar a elaboração dos tópicos da cartilha e de seus conteúdos principais.

A pesquisa foi aprovada pelo Comitê de Ética em Pesquisa da Universidade Estadual do Ceará (parecer $n^{\circ} \quad 939.661 \quad$ e $\quad$ CAEE: 38826214.9.0000.5534), seguindo os preceitos éticos e legais da Resolução $\mathrm{n}^{\circ}$ $466 / 2012$ que versa sobre a pesquisa com seres humanos. ${ }^{15}$ As mulheres atestaram sua participação no estudo mediante assinatura do Termo de Consentimento Livre e Esclarecido (TCLE) fornecido em duas vias: uma para o participante e a outra para o pesquisador.

\section{RESULTADOS}


Das participantes do estudo, dezoito vivenciaram o parto normal e doze, o cesariano. Do total de puérperas, sete eram primíparas e apresentaram faixa etária entre 13 e 40 anos de idade. 26 delas estavam com os filhos no alojamento conjunto. Dentre os recém-nascidos que não estavam junto às mães, citam-se duas crianças internadas em UTI neonatal, uma em berçário de médio risco e uma criança foi a óbito poucas horas após o parto.

A partir dos grupos, surgiram os seguintes temas para discussão sobre o autocuidado da mulher no pós-parto: higiene, nutrição da mãe, cuidados com as mamas, retorno da atividade sexual, planejamento familiar, indicação e retorno de atividade física, perda de peso, repouso, saúde mental e comparecimento às consultas puerperais. Estes foram comuns aos encontrados na revisão integrativa.

As falas correspondentes são as seguintes: Acho que a higiene, evitar infeccionar os pontos, a limpeza [...] Ir para o ginecologista, saber quando pode voltar a ter relação sexual com seu marido [...] A gente tem que ver se pode voltar a fazer todas as atividades que fazia antes da gravidez, ir para a academia [...] Manter a forma que tinha antes de engravidar. Eu acho que uта caminhada não faz mal, quando vai dar banho de sol neles. Uma boa alimentação, alimentação adequada (Gravação 1). A mulher do meu prénatal falou que depois que eu voltar pra casa, elas vão lá para ver como é que tá mãe e bebê [...] Falar sobre amamentação [...] Higiene, principalmente por causa dos pontos, para não inflamar, infectar [...] Caminhar um pouquinho, não fazer esforço (Gravação 2). Repouso, sobre se cuidar, fazer a higiene, boa alimentação, praticar esporte [...] Manter a forma, depois da cesariana, porque você vai ter a instrução, qual exercício pode fazer [...] Ter o cuidado para não pegar outro menino logo, se planejar [...] Trabalhar a mente da mulher [...] Tem que andar um pouquinho, evitar diabetes (Gravação 3). Tomar mais cuidado porque tem infecção, se recuperar bem, usar sabonete líquido para evitar bactéria, trocar absorvente, calcinha [...] Cuidado em geral, alimentação, exercício [...] Educação alimentar, a barriga voltar ao normal, voltar a atividade normal [...] Quanto tempo depois pode fazer exercício físico [...] Que alimentos pode comer (Gravação 5). Quantos meses de recuperação (Gravação 6). Alimentação, a importância da mama (Gravação 8). Com a saúde, cuidado com higiene, do bico do peito para não ferir [...] Boa alimentação (Gravação 9).

Foram acrescentados na cartilha: cuidado com os pontos, cuidados do cabelo e pele, atividades do lar, uso de cinta, benefícios da amamentação para a mulher e apoio familiar. Os produtos que vou poder usar, os que não vou poder, para a pele e os cuidados com o cabelo (Gravação 1). Sobre os pontos, modo de limpar, o produto certo para tomar banho, se pode ser qualquer sabonete líquido, se nenhum arde [...] Saber se os pontos caem, como é que caem, como vou saber se ele cain ou quebrou, se tá tudo bem [...] Não quebrar os pontos (Gravação 2). Não fazer muita força pra não quebra o ponto, se inflamar, pronto (Gravação 3). Botar uma cinta, pode botar ou não? 
(Gravação 5). Se a pessoa pode se baixar, eu vou tá sozinha com o bebê, se eu posso varrer casa. Eu posso usar a cinta ou não, não ser muito acochada (Gravação 6). Eu acho que ajuda do marido sempre é bom, tem marido que não dá muita atenção. Fisicamente a pessoa se cuidar, porque tem gente que não tem autoestima depois do bebê, se descuida, não é motivo, porque tem mulher que não se cuida depois que tem o bebê, então trabalhar a autoestima da mulher, tudo isso colabora para uma vida normal [...] Eu acho assim tendo a mesma atenção, não vai ter o mesmo tempo, mas o máximo que puder, ter cuidado com o seu corpo, às vezes desiste do marido $e$ o companheiro tem que dar autoestima pra ela. Porque tem mulher que se desleixa, vive com barriga alta, não é porque a gente tem filho, não fica o mesmo corpo de antes, mas é porque tem mulher que depois que tem filho, não usa cinta [...] Tem que usar cinta, cuidar das estrias, hidratantes para clarear, aliviar, cicatrizar mais rápido [...] Cuidar da barriga, do corpo, às vezes a mulher se esquece um pouco (Gravação 7). Principalmente de tudo, os cuidados com os pontos (Gravação 8). Eu acho que queria saber principalmente o cuidado dos pontos que leva (Gravação 9).

O cuidado do bebê, por não abordar diretamente o autocuidado da mulher, não foi inserido na cartilha, porém, a amamentação foi brevemente abordada por ser ressaltada pelas mulheres: Como amamentar, questão da saúde do bebê mesmo, se certificar que tá tudo bem com os exames dele. Do umbigo, lavar direitinho [...] Alimentação, as primeiras horas depois do parto, os cuidados (Gravação 4). Se ele não quer mamar ou se eu não quiser dar mais, eu posso parar de dar ou não é bom para o bebê? Se ele não tá conseguindo se satisfazer, eu posso tirar e dar pra ele? Armazenar em vidro? Porque eu trabalho (Gravação 6). Lavar as mãos direto quando for pegar nela, para não pegar bactéria (Gravação 9).

Os temas encontrados na revisão integrativa que não estavam presentes na discussão dos grupos foram inseridos na cartilha por acreditar-se que também tenham relevância, apesar das mulheres não abordarem: suplementação de ferro pela mãe, relaxamento, direitos da mulher, vacinas da mulher no pós-parto e adaptação materna no período.

Dessa forma, sistematizou-se o conteúdo do material: "Pós-parto: o que é?"; "Higiene é fundamental" ("Produtos para os cabelos e pele" e "Cuidados com os pontos"); "Alimentação adequada"; "Cuidados com as mamas e amamentação" ("Vantagens da amamentação para a mulher"); "Quando o casal pode voltar a ter relação sexual?" ("Planejamento familiar" e "Compareça sempre às consultas"); "Repouso" ("Tarefas domésticas"); "Exercícios físicos e perda de peso" ("Perda de peso e barriga" e "Uso de cinta"); "Cuide da mente" ("É preciso relaxar"); "Vitaminas e vacinas" ("Veja se já tomou todas as vacinas"); "Direitos da mulher"; e, "Ajuda da família".

\section{DISCUSSÃO}

Quanto à característica dos grupos de puérperas, salienta-se que foram 
bastante heterogêneos por conta da natureza de sua formação, que foi por acessibilidade. As enfermarias apresentavam mulheres com perfis obstétricos e idades variados, além de acompanhantes com diferentes graus de parentescos, citando-se mães, irmãs e sogras. Tal característica conferiu riqueza e dinamismo nas interações entre as participantes, por permitir a partilha de diferentes experiências e realidades entre elas.

O puerpério é considerado uma fase de modificações biossocioculturais que muitas vezes não são compreendidas pela mulher, o que exige maior atenção dos profissionais, dos familiares e das redes de apoio envolvidos em seu cuidado. ${ }^{16} \mathrm{O}$ cuidado com a imagem corporal e com a mente, evidenciado tanto pelas mulheres deste estudo como pela literatura, destaca a importância do autocuidado durante o pósparto para a autoestima e bem-estar da mulher, bem como para evitar possíveis transtornos psicoafetivos, como a depressão pós-parto. ${ }^{11}$

Nesse período é comum as mulheres sentirem-se emocionalmente vulneráveis frente à insegurança, ansiedade e dúvidas que permeiam tanto o cuidado com o recém-nascido, quanto os reajustes familiares necessários e o autocuidado. ${ }^{17}$ Há necessidade de reorganização social e adaptação a um novo papel. A mulher tem um súbito aumento de responsabilidade por se tornar provedora de cuidados a uma pessoa indefesa, podendo sofrer privação de sono, isolamento social e estresse. Além disso, é preciso reestruturação $\mathrm{da}$ sexualidade, da imagem corporal e da identidade feminina. Devido a isso, é necessário que o cuidado nesse período não envolva somente a dimensão biológica, mas que ele também contemple a dimensão psicológica, afetiva e social da mulher. $^{11}$

No universo consensual das puérperas e das acompanhantes do estudo o período pós-parto é percebido como um momento em que é indispensável ter bastante cuidado, atenção e repouso, de forma a garantir a sua recuperação e evitar possíveis complicações. Algumas expressões, tais como não fazer esforço, repouso e não pegar peso são consideradas fundamentais para o restabelecimento da saúde da mulher. Isto também é percebido em outro estudo ${ }^{11}$, em que as puérperas ancoram o resguardo na dimensão do cuidado e da precaução, uma vez que simbolizam esse período como um momento de perigos e fragilidades, em que é necessário seguir determinadas restrições para evitar consequências ruins.

Neste contexto de atenção às puérperas, as práticas de enfermagem têm 
emergido através do incentivo e orientações sobre o autocuidado da puérpera. Considera-se que o autocuidado é a escolha livre e autônoma de ferramentas que irão promover uma atenção, bem como a ação do indivíduo sobre si mesmo para manter uma qualidade de vida de maneira responsável. É adotar medidas de prevenção de doenças e controlar fatores de risco, buscar hábitos de vida saudáveis e melhorar o estilo de vida. $^{18}$

$\mathrm{O}$ fato de ser mulher, na perspectiva familiar e antropológica, mostra a importância e a responsabilidade da puérpera pelo cuidado. Por meio da história da civilização humana, as mulheres são responsabilizadas pela promoção do cuidado, com o intuito de contribuir para a continuidade da vida. Além disso, a mulher seria responsável tanto pelo autocuidado como pelos cuidados dos familiares que, no caso das puérperas, são representados pelo recémnascido e pelo companheiro. ${ }^{16}$

Percebe-se que quando a mulher não dispõe do suporte familiar para lhe ajudar no período pós-parto, o que é evidenciado em uma das falas, as suas responsabilidades e afazeres aumentam significativamente, uma vez que ela deve prover o cuidado à casa, ao marido, ao recém-chegado filho e o cuidado consigo, sobrecarregando essa mulher e fazendo com que ela não se dedique ao seu cuidado. Quando a puérpera não pode contar com a ajuda contínua de algum membro da família, o seu autocuidado fica em segundo plano, uma vez que o contexto em que vive e as suas atribuições não permitem que ela tenha condições de cuidar de si mesma. ${ }^{11}$

No período pós-parto, o cuidado recebido e o autocuidado são envolvidos por influências, crenças e práticas, que são passadas de geração em geração. Tais influências têm origem nos relatos de sucessos e insucessos ocorridos no pósparto das mulheres da família. São histórias e vivências que, muitas vezes, despertam tanta confiança, que acabam sendo percebidas como verdades absolutas e, assim, são seguidas sem questionamentos. Inúmeras podem ser as fontes que influenciam no preparo da mulher para o adequado autocuidado nesse período, entre elas citam-se a equipe de saúde, a mídia, os conselhos de mães, avós e amigas leigas. ${ }^{16-17}$

Orem identifica os cinco métodos de ajuda a seguir: agir ou fazer para outra pessoa; guiar e orientar; proporcionar apoio físico e psicológico; proporcionar e manter um ambiente de apoio ao desenvolvimento pessoal; ensinar. $\mathrm{O}$ sistema totalmente compensatório é 
representado pela situação em que o indivíduo é socialmente dependente de outros para continuar a sua existência e o seu bem-estar. O sistema de enfermagem parcialmente compensatório é representado pela situação na qual tanto enfermeiro quanto paciente desempenham medidas de cuidados. No sistema de apoio-educação a pessoa é capaz de desempenhar, ou pode e deve aprender a desempenhar, as medidas exigidas pelo autocuidado, externa ou internamente orientado, mas pode fazer isso sem assistência. ${ }^{7}$

A enfermagem deve então agir conforme as reais necessidades apresentadas por essas mulheres, elaborando um plano assistencial que possibilite à puérpera uma boa adaptação a esta fase, instrumentalizando-a não só para prover os cuidados com o filho, mas principalmente para realizar o seu autocuidado, de modo a obter os conhecimentos e a segurança necessária durante esse período. ${ }^{11} \mathrm{O}$ saber científico deve chegar às mulheres através de orientações claras e vocabulário acessível no intuito de reforçar a educação em saúde; a imposição de condutas precisa ser evitada dando lugar à negociação e compartilhamento de saberes. ${ }^{17}$

Para o alcance disso, cabe à enfermagem desenvolver também ações de educação em saúde que não se traduza no simples repasse de informações, mas que se caracterize como uma prática articulada às expectativas e demandas das puérperas. Somente assim, as atividades educativas serão efetivas e condizentes com as necessidades encontradas. Uma boa orientação, devidamente contextualizada ao cuidado e embasada em uma relação de confiança entre enfermeiro-puérpera, poderá repercutir não só na qualidade dos sentimentos manifestos pela mulher, mas também culminar em uma adaptação saudável da puérpera ao seu papel materno. ${ }^{11}$

Os cuidados no pós-parto devem ser conhecidos não só por profissionais, mas principalmente pela mulher e seu meio familiar e social. No contexto da enfermagem, baseando-se nas bases filosóficas e teóricas que constituem o cuidado, evidencia-se na teoria de Orem, a qual afirma que o autocuidado é um ato de indivíduos, condicionado por crenças culturais, costumes e hábitos da família e da sociedade, a possibilidade de identificar o conhecimento e a educação que cada mulher tem para nortear suas ações e evitar complicações durante o pós-parto. ${ }^{19}$

Assim, o indivíduo deve ter suficiente prática de autocuidado para satisfazer as suas próprias necessidades. No entanto, em situações nas quais ocorre a demanda pelo cuidado e o indivíduo não 
é capaz de manter sua autonomia para tal, seja parcial ou completamente, os enfermeiros são responsáveis por auxiliar no desenvolvimento desta prática. Desta forma, é importante que as mulheres estejam conscientes das exigências de autocuidado neste momento, assim como de suas próprias falhas de autocuidado para determinar se elas precisam da ajuda de enfermeiros. $^{17}$

Estes profissionais devem atuar como facilitadores, na motivação para as mudanças comportamentais desejáveis, e apoiar o desenvolvimento ou fortalecimento de habilidades para $o$ autocuidado. Portanto, o processo educativo para as atividades de autocuidado deve ser contínuo e atualizado de acordo com as necessidades do público alvo. $^{20}$

\section{CONCLUSÃO}

O desenvolvimento desta pesquisa possibilitou aproximação teórica para desenvolver assistência direcionada às reais demandas das puérperas a partir da identificação das necessidades de autocuidado e expectativas das próprias participantes. $\mathrm{O}$ recurso permitiu $\mathrm{o}$ compartilhamento de saberes e promoveu a contribuição ativa na elaboração do conteúdo do material.
De um modo geral, as necessidades envolveram principalmente repouso, cuidado com as suturas, alimentação adequada e higiene, sendo estas relacionadas ao cuidado com o corpo, de modo a garantir a recuperação da mulher neste período da vida e a evitar possíveis complicações no puerpério.

Pretende-se que o conhecimento gerado no estudo possa servir como dispositivo importante a ser utilizado pelos serviços que prestam assistência à mulher, implicando em uma melhor qualidade do acompanhamento às puérperas.

Como limitação deste estudo evidencia-se que, embora tenham sido definidos critérios para seleção das participantes bem como o local da pesquisa, não é possível generalizar seus achados. Desta forma, sugere-se que esta temática seja investigada em outros espaços para que se identifiquem outras possíveis demandas das puérperas, contribuindo para a melhor qualidade da assistência de enfermagem.

\section{REFERÊNCIAS}

1. Acevedo-Hernández BA, Pizarro N, Moriel-Corral BL, González-Carrillo E, Berumen-Burciaga LV. Proceso educativo de enfermería para promover el autocuidado de la mujer durante el puerpério. Rev Enferm Inst Mex Seguro Soc. 2016; 24(3):197-204.

2. Andrade RD, Santos JS, Maia MAC, Mello DF. Fatores relacionados à saúde da 
mulher no puerpério e repercussões na saúde da criança. Esc Anna Nery Rev Enferm. 2015; 19(1):181-6.

3. Oliveira JFB, Quirino GS, Rodrigues DP. Percepção das puérperas quanto aos cuidados prestados pela equipe de saúde no puerpério. Rev RENE. [Internet]. 2012 [citado em 16 ago 2015]; 13(1):74-84. Disponível em::

http://periodicos.ufc.br/rene/article/view/3 $772 / 2984$

4. Queirós PJP, Vidinha TSS, Almeida Filho AJ. Autocuidado: o contributo teórico de Orem para a disciplina e profissão de enfermagem. Rev Enf Ref. [Internet]. 2014 [citado em 22 jul 2018]; 4(3):157-64. Disponível em: http://www.scielo.mec.pt/pdf/ref/vserIVn3/ serIVn3a18.pdf

5. Schmalfuss JM, Prates LA, Azevedo M, Schneider V. Diabetes melito gestacional e as implicações para o cuidado de enfermagem no pré-natal. Cogitare Enferm. 2014; 19(4):815-22.

6. Alves MS, Araújo MCF, Nascimento MP, Ribeiro FC, Rebouças PT, Santos TA et al. Therapeutic group with seniors about self-care in chronic diseases. J Health Sci. 2016; 18(1):48-51.

7. Orem DE. Nursing: concepts of practice. 6th ed. New York: McGraw-Hill; 2001.

8. Hickman JS. Introdução à teoria da enfermagem. In: George JB. Teorias de enfermagem: os fundamentos à prática profissional. 4ed. Porto Alegre: Artes Médicas Sul; 2000. p.11-20.

9. Vitor AF, Lopes MVO, Araujo TL. Teoria do déficit de autocuidado: análise da sua importância e aplicabilidade na prática de enfermagem. Esc Anna Nery Rev Enferm. 2010; 14(3):611-6. 10. Progianti JM, Costa RF. Práticas educativas desenvolvidas por enfermeiras: repercussões sobre vivências de mulheres na gestação e no parto. Rev Bras Enferm. [Internet]. 2012 [citado em 16 ago 2015]; 65(2):257-63. Disponível em: http://www.scielo.br/pdf/reben/v65n2/v65n 2a09.pdf
11. Dodou HD. Representações sociais de puérperas sobre o autocuidado e o cuidado de enfermagem no puerpério. [dissertação]. Fortaleza: Universidade Estadual do Ceará; 2015.

12. Reberte LM, Hoga LAK, Gomes ALZ. O processo de construção de material educativo para a promoção da saúde da gestante. Rev Latinoam Enferm. 2012; 20(1):[08 telas].

13. Barbosa EMG, Sousa AAS, Vasconcelos MGF, Carvalho REFL, Oriá MOB, Rodrigues DP. Educational technologies to encourage (self) care in postpartum women. Rev Bras Enferm. 2016; 69(3):545-53.

14. Mendes KDS, Silveira RCCP, Galvao

CM. Revisão integrativa: método de pesquisa para a incorporação de evidências na saúde e na enfermagem. Texto \& Contexto Enferm. [Internet]. 2008 [citado em 16 ago 2015]; 17(4):758-64.

Disponível em:

http://www.scielo.br/pdf/tce/v17n4/18.pdf 15. Conselho Nacional de Saúde (Brasil), Comissão Nacional de Ética em Pesquisa. Resolução no 466, de 12 de dezembro de 2012. Diretrizes e normas regulamentadoras de pesquisa envolvendo seres humanos. Brasília, DF: CNS; 2012. 16. Baraldi NG. Período pós-parto: práticas de cuidado adotadas pela puérpera. [dissertação]. São Paulo: Universidade de São Paulo; 2012.

17. Acosta DF, Gomes VLO, Kerber NPC, Costa CFS. Influências, crenças e práticas no autocuidado das puérperas. Rev Esc Enferm USP. 2012; 46(6):1327-33. 18. Costa NS, Soares MBO, Melo MM, Parreira BDM, Silva SR. Prática do autocuidado e demandas por cuidados de enfermagem pelas puérperas. Rev Enferm Atenção Saúde. 2013; 2(1):75-88. 19. Nazik E, Eryilmaz G. The prevention and reduction of postpartum complications: Orem's model. Nurs Sci Q. 2013; 26(4):360-4.

20. Coelho ACM, Villas Boas LCG, Gomides DS, Foss-Freitas MC, Pace AE. Self-care activities and their relationship to 
metabolic and clinical control of people with diabetes mellitus. Texto \& Contexto

Enferm. 2015; 24(3):697-705.

RECEBIDO: 02/01/2017

APROVADO: $17 / 07 / 2018$

PUBLICADO: 07/2018 